\title{
TRANSVERSE TESTS OF H-SECTION COLUMN SPLICES
}

\author{
By James H. Edwards, H. L. Whittemore, and A. H. Stang
}

\section{ABSTRACT}

Plates were welded to the outer edge of the inside faces of the flanges of 3 -foot lengths of 10,12 , and 14 inch $H$ sections. The $H$ sections were joined in pairs by splice plates bolted to these welded plates to represent a spliced section of column for use in a steel-frame building. The specimens so formed were tested as beams on a 66-inch span with loads at the quarter points. Four specimens were tested with the splice plates and $\mathrm{H}$ section webs parallel to the applied loads which were in a vertical plane; three specimens were tested with the splice plates and $H$ section webs perpendicular to the applied loads.

The behavior of the specimens is described and a method of stress analysis suitable for use in designing similar splices is developed.

\section{CONTENTS}

I. Introduction

II. Specimens

III. Test procedure

1. Loading of specimens

IV. Test results

V. Analysis of data

1. Stress

2. Deflection

VI. Discussion

1. Method of analysis

2. Stress

(a) $\mathrm{H}$ sections

(b) Plates

(c) Bolts

(d) Welds

3. Deflection

4. Combined loading

\section{INTRODUCTION}

Steel structures are composed of large members, such as columns and floor beams, joined or fastened together with small plates, angles, or other shapes which are commonly referred to as structural details. The complex distribution of stress in the details requires that tests be made to show whether the methods used in determining the size of the details result in safe and economical structures. If for some reason a detail is changed, further tests should be made to determine the effect of the change.

The adoption of welding in the fabrication and erection of structural steel has brought about the modification of many structural details. The present investigation was undertaken to determine the effect of substituting welding for riveting in the fabrication of details used in splicing columns of steel-frame buildings and of changing the location of the splice plates from a position parallel to the flanges of the columns to one parallel to the webs of the columns.

The columns of steel-frame buildings are commonly made in 2-story lengths and are connected at alternate floors by splices. The weight of the structure and its contents and the wind pressure against the 
structure produce compressive, bending, and shearing stresses in the columns and splices. At the column connections or joints, the splice plates joining the ends of the columns resist the bending and shearing stresses. The compressive stress at the joints is commonly assumed to be carried by the columns only. The stress is transferred from the upper to the lower column by bearing.

The tests reported in this paper were made to investigate the strength and other properties of welded splice connections of $\mathrm{H}$ sections subjected to bending. No tests were made to determine the resistance of this type of connection to shearing stresses.

Columns in steel-frame buildings are commonly 10,12 , or 14 inches wide. Data on the strength of splices of these sizes of columns were desired, using as few specimens as possible. As wind pressure on a building may produce loads on the columns in the direction of either of the transverse axes, it was necessary to test some specimens under loads parallel to one axis and other specimens under loads parallel to the other axis.

Because the specimens were loaded as simple beams, they will be called "beams" in this report. It should be remembered, however, that they represent spliced column sections under the action of bending stresses.

The American Bridge Co. furnished the specimens which were designed by James H. Edwards, chief engineer. O. E. Hovey, assistant chief engineer, and other members of the company's engineering staff assisted in making the tests. Prof. Elmer O. Bergman, research associate, contributed considerably to the analysis of the test data and edited the manuscript.

\section{TABLE OF SYMBOLS}

$B_{U}=$ Force exerted by upper bolts on plate.

$B_{L}=$ Force exerted by lower bolts on plate.

$C=$ Resultant compressive force.

$T=$ Resultant tensile force.

N. $A .=$ Neutral axis.

$C_{1}=$ Compressive force on upper flange of $\mathrm{H}$ beam at spliced section.

$C_{2}=$ Resultant of $B_{U}$ and $C_{1}$.

$C_{3}=$ Resultant of $W_{U}$ and $C_{1}$.

$W_{U}=$ Force exerted through upper weld on $\mathrm{H}$ beam.

$W_{L}=$ Force exerted through lower weld on $\mathrm{H}$ beam.

$S_{t}=$ Tensile stress.

$S_{c}=$ Compressive stress.

$S_{s}=$ Shear stress in bolts.

$S_{s w}=$ Shear force per unit length in weld.

\section{SPECIMENS}

Plates were placed parallel to the webs of the $\mathrm{H}$ sections and welded to the inside faces of the flanges as shown at $A$ in Figure 1. The welds for the 10 and 14 inch $\mathrm{H}$ sections with the exception of column C14-B3B2W, which had fillet welds, were single-bevel butt welds as shown in Figures 2 and 3 . The welds for the 12-inch $\mathrm{H}$ sections were $5 / 16$-inch fillet welds as shown in Figures 4 and 5 . The distance from the ends of the plates to the ends of the $\mathrm{H}$ sections was onehalf inch. The angles welded to the $\mathrm{H}$ section at $B$ in Figure 1 were 
B. S. Journal of Research, RP157

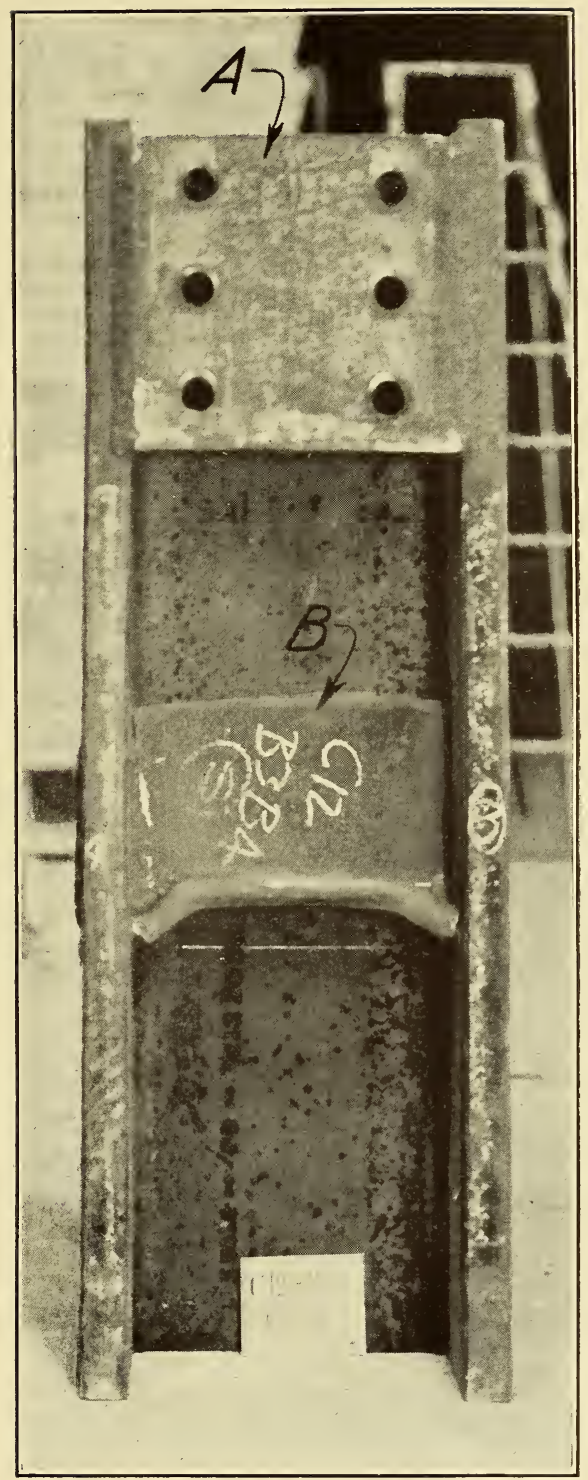

Figure 1.-H section showing plate welded to inside faces of flanges at $A$ 
used in an investigation of the strength of welded shelf angles which will be reported in a later paper.

The $H$ sections were 3 feet long and 10,12 , or 14 inches wide. They were fastened together in pairs with either two or four splice plates bolted to the plates which had been welded to the $\mathrm{H}$ sections.
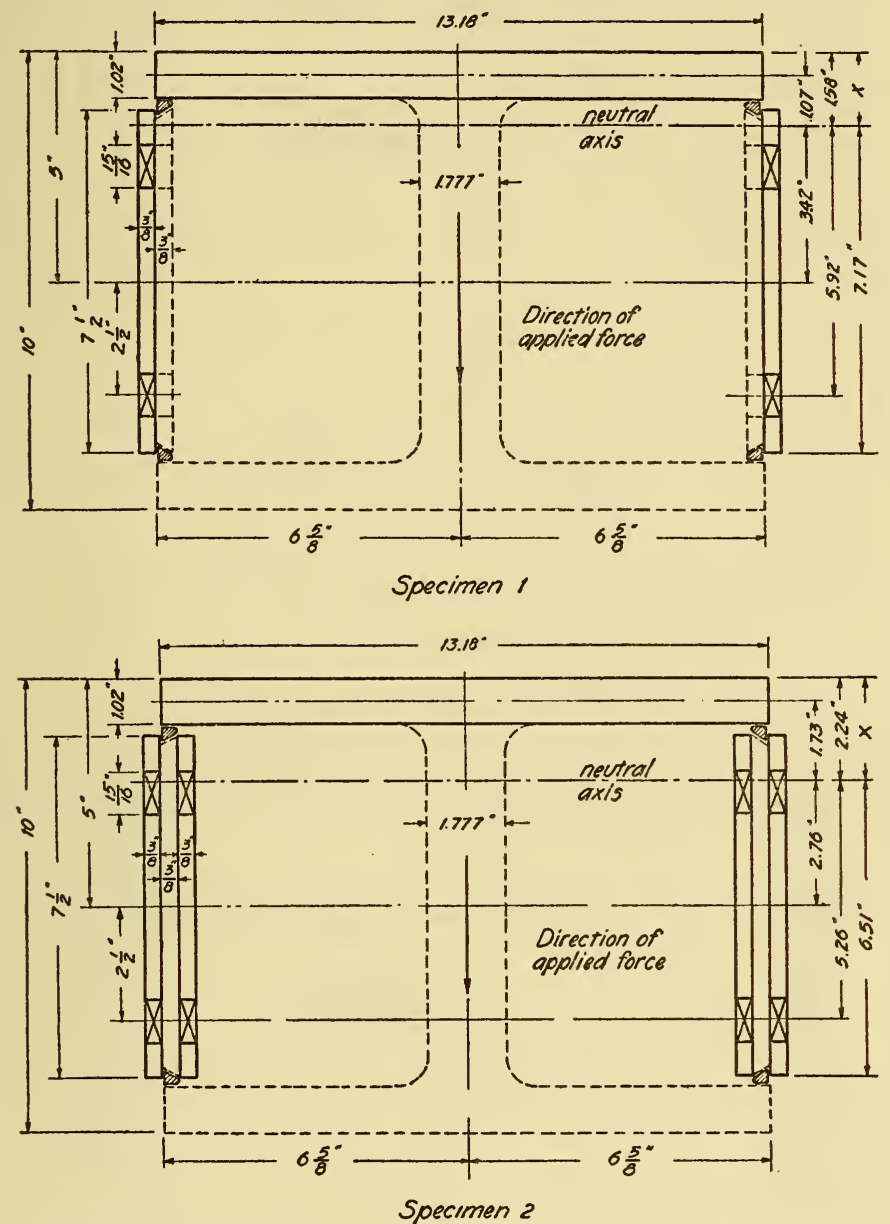

FigURE 2.-Specimen 1; column C10-B1B4; column C10B2B4; single splice plates, SP1, load parallel to the web of the $\mathrm{H}$ sections. Specimen 2, column C10-B1B4, column C10-B2B4, double splice plates SP1, load parallel to the web of the $\mathrm{H}$ sections

Cross section at splice of specimens with loads parallel to web, showing position of neutral axis. Portions carrying stress indicated by full lines.

The bolts were seven-eighths inch in diameter and were placed in two rows parallel to the longitudinal axes of the $H$ sections. The plates had 15/16-inch punched holes. One splice plate was placed outside the welded plates on each side of the specimens that had single splice plates. (Figs. 2 to 6.) Two splice plates, one inside and one outside the welded plates, were used on each side of the specimens that had double splice plates. (Fig. 7.) 

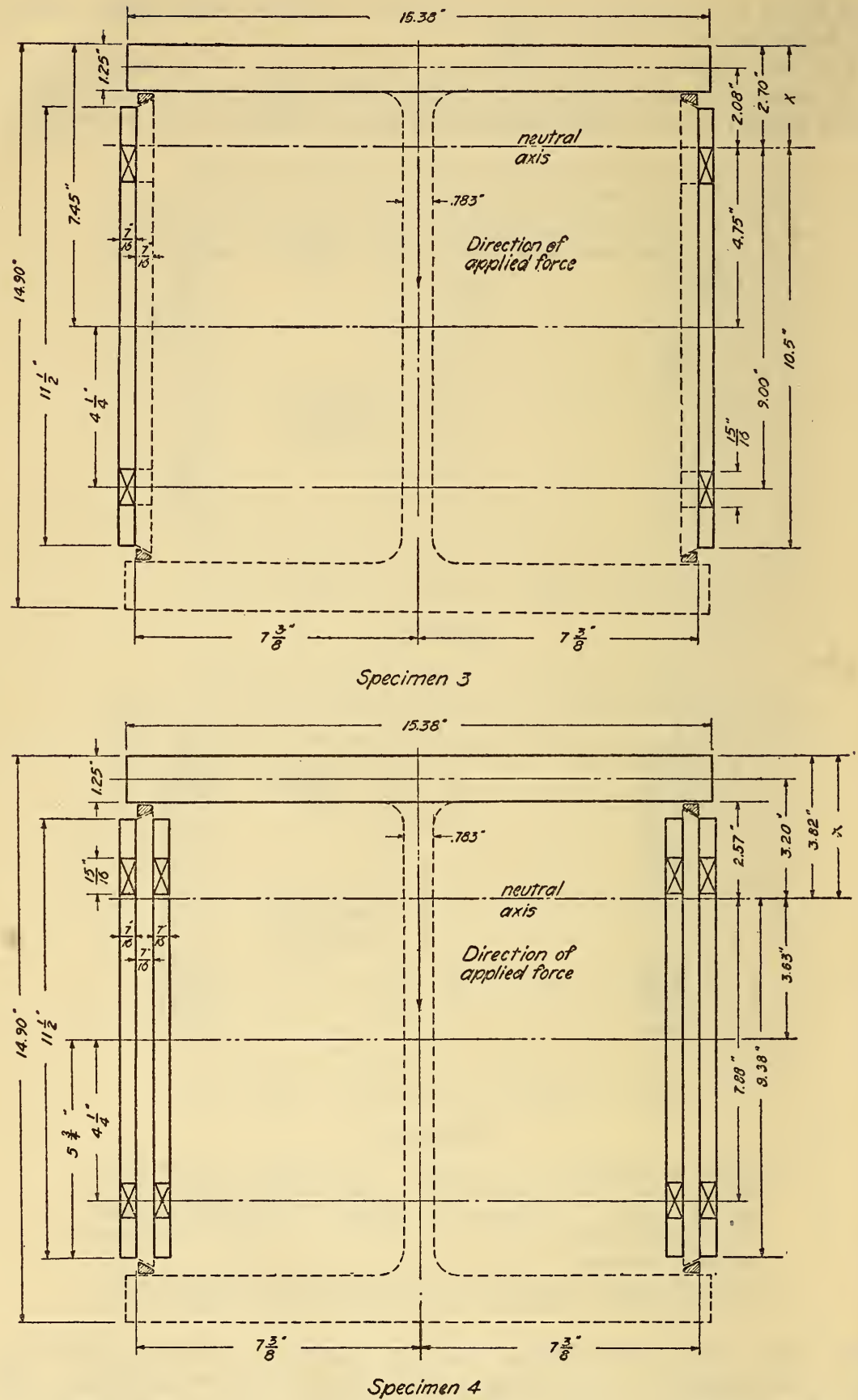

Frgure 3.-Specimen 3, column C14-B1B4, column C14-B2B4, single splice plates, SP3, load parallel to the web of the $\mathrm{H}$ sections. Specimen 4 , column C14-B1B4, column C14-B2B4, double splice plates, SP3, load parallel to the web of the $\mathrm{H}$ sections

Cross section at splice of specimens with loads parallel to web, showing position of neutral axis. Portions carrying stress indicated by full lines. 


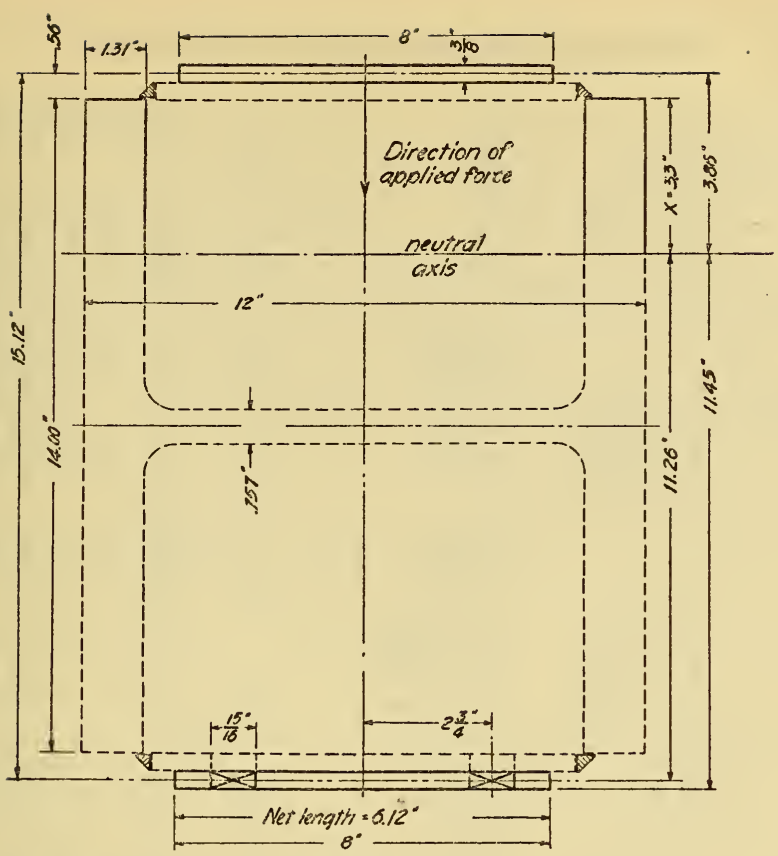

Specimen 5

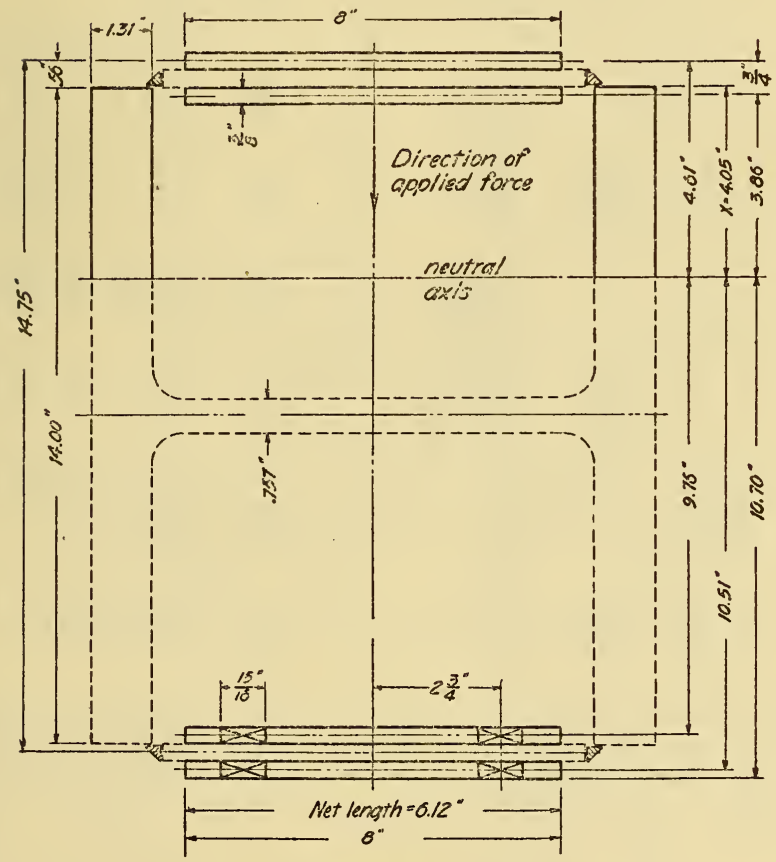

Specimen 6

FIgURE 4.-Specimen 5, column C12-B3B4; single splice plates, SP2; load perpendicular to web of the $\mathrm{H}$ sections. Specimen 6; column C12-B1B2W; column C12-B3B4, double splice plates, SP2; load perpendicular to the web of the $\mathrm{H}$ sections

Cross section at splice of specimens with loads perpendicular to web showing position of neutral axis. Portions carrying stress indicated by full lines. 


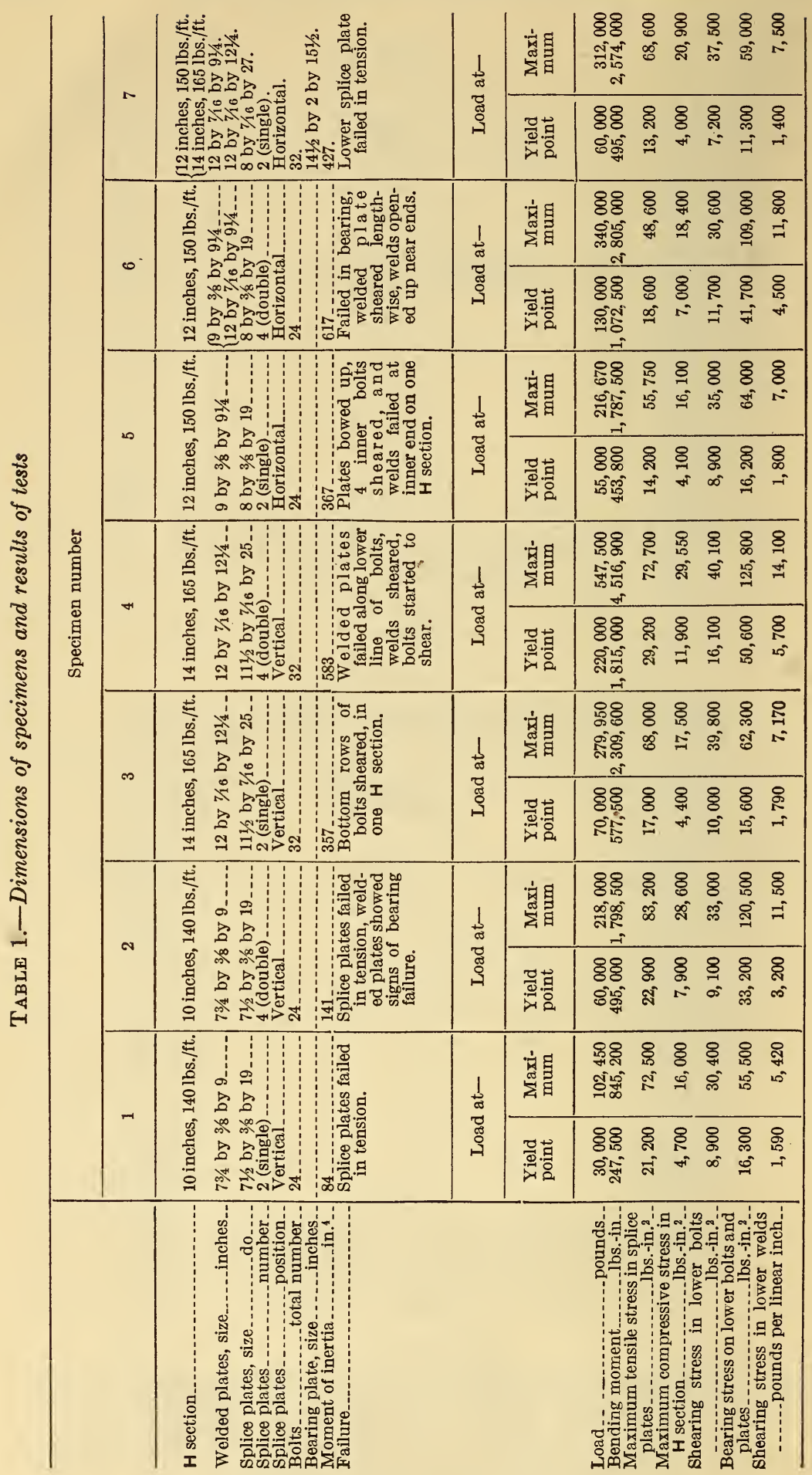


The properties and dimensions of the specimens are given in Table 1. Figure 7 shows a specimen in the machine before testing. The cross sections of the specimens are given in Figures 2 to 5 . The dimensions of the $\mathrm{H}$ sections are the nominal dimensions given in Carnegie Beam Sections (1st ed., 1927).

Four specimens were tested with the loads parallel to the splice plates and to the webs of the $\mathrm{H}$ sections as shown in Figure 7 . Two of these were composed of 10 -inch $\mathrm{H}$ sections (fig. 2), the other two were of 14-inch $\mathrm{H}$ sections (fig. 3). One specimen of each size had single, the other had double splice plates. The same $\mathrm{H}$ sections were

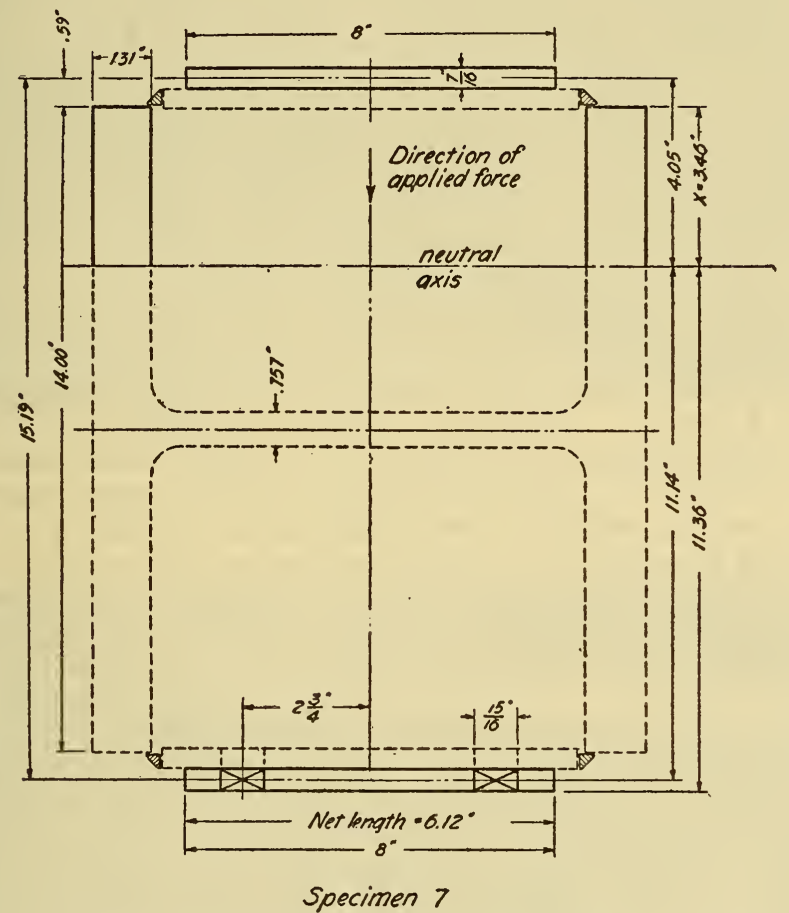

Figdre 5.-Specimen 7, column C14-B3B2W, column C12-B1B2W, bearing plate, C12F, between columns, single splice plates, SP 4, load perpendicular to the web of the $\mathrm{H}$ sections

Cross section at splice of specimens with loads perpendicular to web showing position of neutral axis. Portions carrying stress indicated by full lines.

used for the specimens with single and with double splice plates, the specimens with single plates being tested first. It was believed that the behavior of 12 -inch specimens could be predicted with sufficient accuracy for design purposes from the data on the 10 and 14 inch specimens.

Three specimens were tested with loads perpendicular to the splice plates and webs as shown in Figure 6. One specimen consisted of 12-inch $\mathrm{H}$ sections and single splice plates and one of 12 -inch $\mathrm{H}$ sections and double splice plates. (Fig. 4.) Used in conjunction with the data from specimens with loads parallel to the splice plates, the 
results from these two specimens should give a good indication of the behavior of the 10 and 14 inch specimens under loads perpendicular to the splice plates. The third specimen in this group consisted of one 12-inch and one 14-inch $\mathrm{H}$ section with a bearing plate between and with single splice plates. (Fig. 5.) It was included to show the effect of a difference in width of the $\mathrm{H}$ sections.

\section{TEST PROCEDURE}

\section{LOADING OF SPECIMENS}

Specimens 1, 3, and 5 were tested in the bureau's 600,000-pound capacity testing machine. Because of the larger loads required to produce failure, the other specimens were tested in the $10,000,000-$ pound capacity machine. The specimens were tested as simple beams on a 66-inch span with loads applied at the quarter points.

In the 600,000 -pound machine the specimen was placed on $2 \frac{1}{2}$-inch rollers which were free to roll so as to avoid axial constraint in the specimen. A loading beam rested on 2-inch rollers placed on the specimen at the quarter points. The spherical bearing block of the testing machine was applied to a 2-inch roller placed at the midspan of the loading beam.

The method of loading specimens in the 10,000,000-pound machine is shown in Figure 7 . The pins in the end supports were $2 \frac{1}{2}$ inches in diameter and the rollers at the quarter points of the specimen were 2 inches in diameter. The lower platen of the testing machine has a spherical bearing which was adjusted at the beginning of a test to produce equal bearing on the rollers on the top of the specimen. No provision was made to eliminate axial constraint in these specimens. It was decided that the expense of providing the required number of rollers to permit longitudinal movement was not justified.

\section{MEASUREMENT OF DEFLECTION}

Wires were stretched on each side of the specimens between points directly over the supports as shown in Figure 7. The deflections of the specimens were obtained by observing the positions of the wires in a mirror having a scale attached. The scale was graduated in tenths of an inch and the deflection was read by estimation to the nearest hundredth of an inch. Readings were taken at 5,000-pound increments of load for specimens 1 and 5, and at 10,000-pound increments for the others.

\section{TEST RESULTS}

The load-deflection curves for the specimens are shown in Figure 8. Figure 9 gives the curve for specimen 4 plotted to a scale which allows the deflection at higher loads to be shown. The cross lines on the curves of Figures 8 and 9 are placed at the loads for which the deflection ceased to be proportional to the loads, and these values are listed in Table 1 as "yield point" loads. The maximum load for each specimen is also given in Table 1. The meaning of the dash lines in Figures 8 and 9 will be explained later.

A detailed account of the behavior of the specimens follows.

Specimen 1.-Ten-inch $\mathrm{H}$ sections, single splice plates, loads parallel to web. The splice plates failed in tension across the net section 


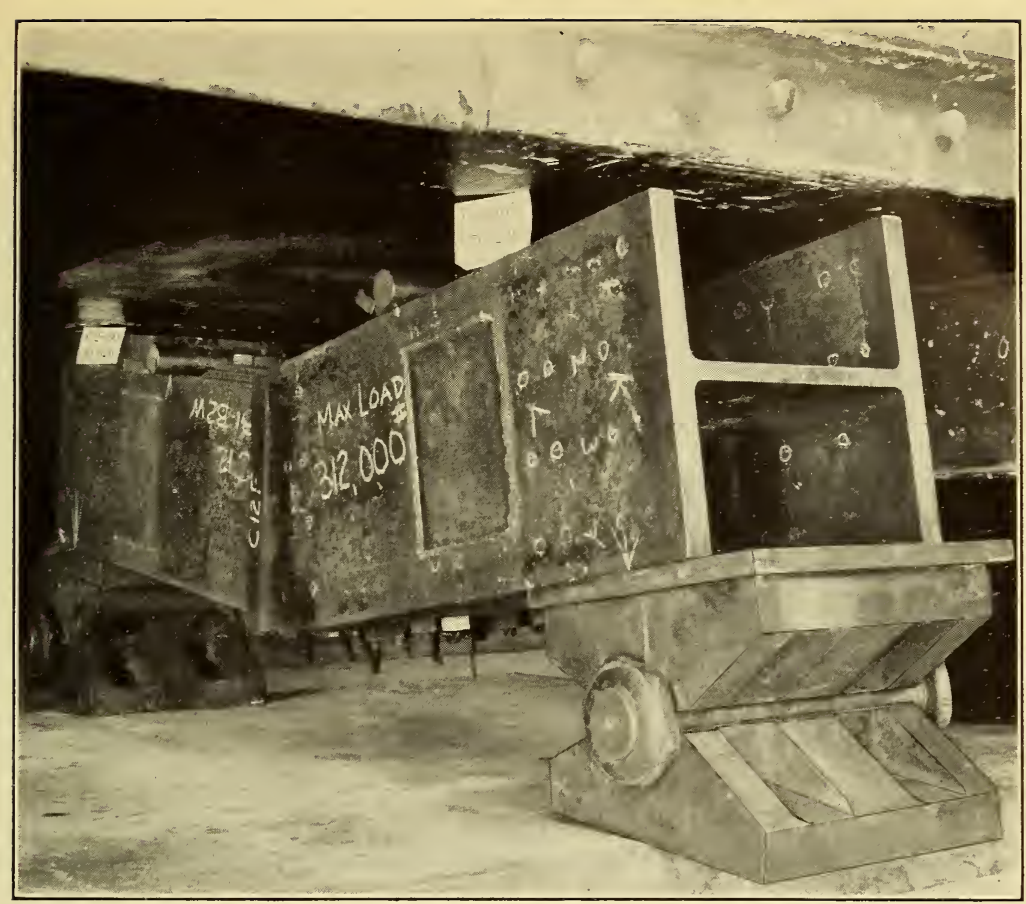

FIGURE 6.-Specimen 7 after transverse test; 12-inch and 14-inch $\mathrm{H} \mathrm{sec-}$ tion with bearing plate, loads perpendicular to web

Lower splice plate failed in tension.

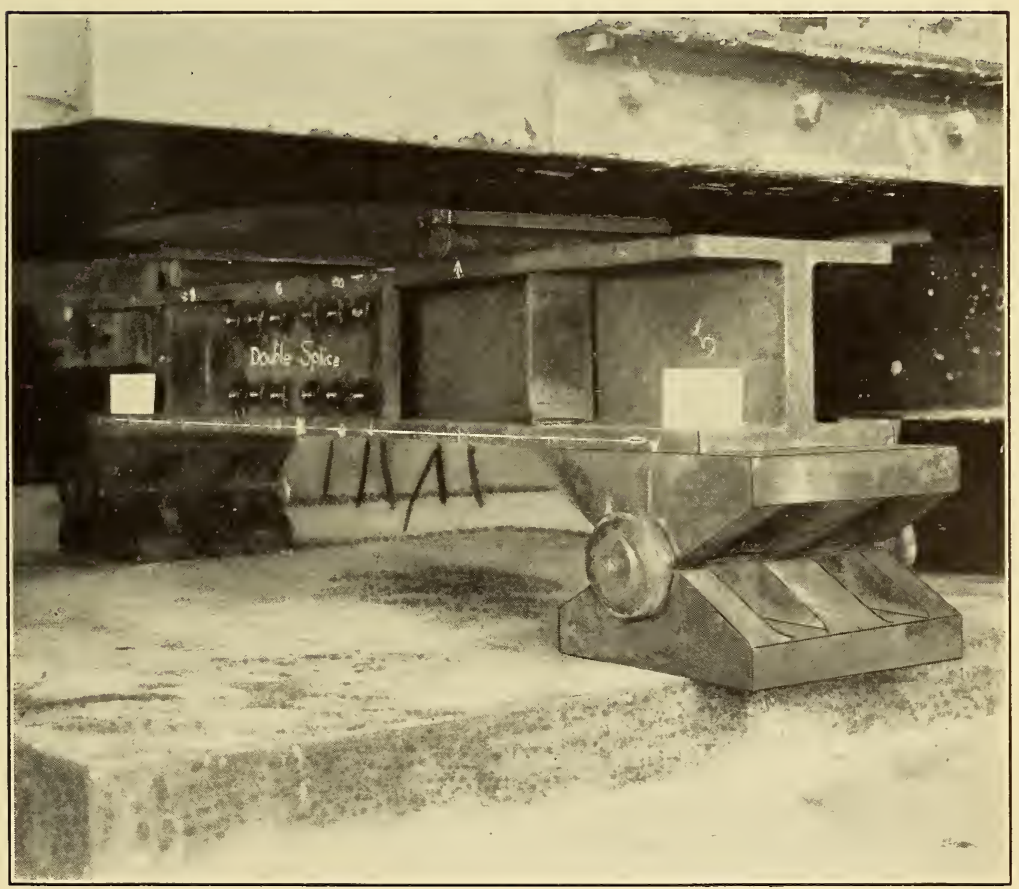

Figure 7.-Specimen 2 before the transverse test; two 10-inch $\mathrm{H}$ sections; loads parallel to web

Splice plates failed in tension; welded plates showed signs of bearing failure. 


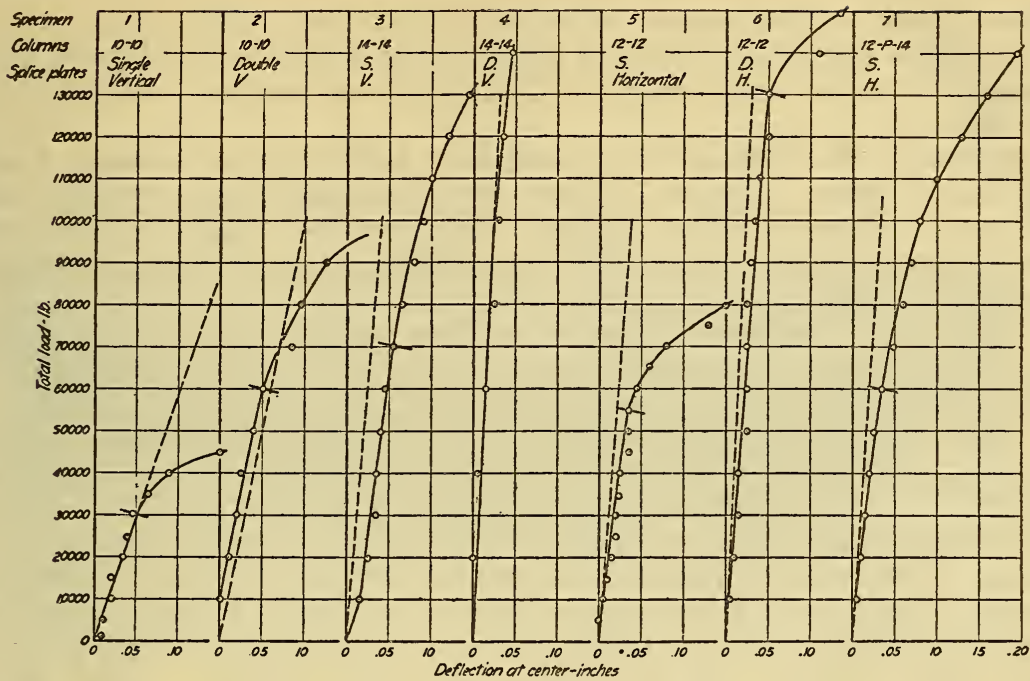

Figure 8.-Load-deflection curves for spliced $\mathrm{H}$ sections, specimens 1-7.

Full lines indicate measured deflection. Dash lines are deflection of a beam with similar loading

having a constant moment of inertia equal to that computed for the weakest section of the test beam.

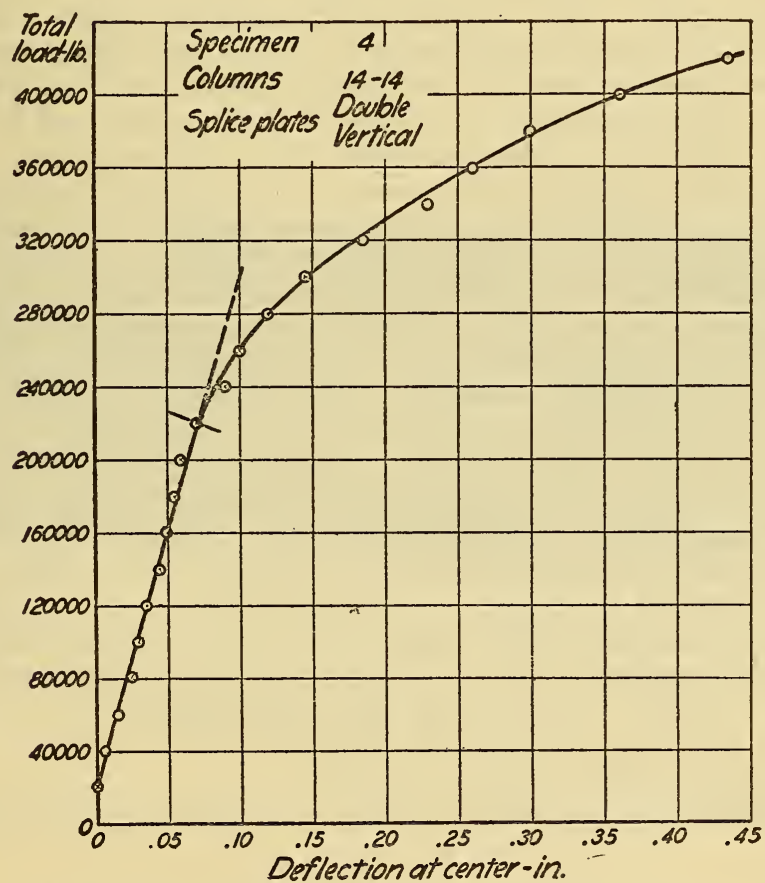

Figure 9.-Load-deflection curve for spliced $\mathrm{H}$ sections, specimen 4, showing deflection at higher loads 
through one of the groups of holes nearest the middle of the plate. The failure began at the lower edges of the plates and extended progressively to the upper holes. The failure was similar to that shown in Figure 10.

Specimen 2.-Ten-inch $\mathrm{H}$ sections, double splice plates, loads parallel to web. Figure 7 shows the specimen before testing, and Figure 10 shows it after testing. This specimen failed in the same way that specimen 1 did. The lower holes in the welded plates were badly deformed.

Specimen 3.-Fourteen-inch $\mathrm{H}$ sections, single splice plates, loads parallel to web. The splice plates scaled at a load of 218,000 pounds. The eight lower bolts in one of the $\mathrm{H}$ sections sheared.

Specimen 4.-Fourteen-inch $\mathrm{H}$ sections, double splice plates, loads parallel to web. Figure 11 shows the specimen after test with the splice plates in place, and Figure 12 shows it with one outer splice plate removed. The welded plates failed in bearing against the bolts. The holes elongated noticeably and one plate split between holes. The top and bottom welds of one plate on one side of the specimen failed. On the other side of the specimen the top weld of one plate and the bottom weld of the other failed. These weld failures occurred after the maximum load on the specimen had been reached. The lower rows of bolts started to shear. The webs of the $H$ sections over the supports scaled, and the $H$ sections were permanently bent and distorted.

Specimen 5.-Twelve-inch $\mathrm{H}$ sections, single splice plates, loads perpendicular to web. The welded plates and the splice plate on the lower side of the specimen deformed, as the deflection increased, so that the longitudinal axis of the plates approached the webs of the $\mathrm{H}$ sections. The welds in one of the $\mathrm{H}$ sections sheared for a length of 3 inches beginning at the inner end of the welded plate. The four bolts nearest the middle of the joint in this $\mathrm{H}$ section sheared.

Specimen 6.-Twelve-inch $\mathrm{H}$ sections, double splice plates, loads perpendicular to web. Figure 13 shows the specimen after test with the bottom splice plate removed. Only one $\mathrm{H}$ section from specimen 5 could be used in this specimen as the lower welded plate of the other sheared. The 12-inch $\mathrm{H}$ section from specimen 7 was substituted. The welded plates on this section were longer and thicker and had two additional holes. Since the splice plates were symmetrical, these two extra holes were not used. The thinner welded plate on the lower side of the specimen failed in bearing against the bolts. The holes elongated and the plate sheared between the holes. The welds failed for a short distance beginning at the outer end of the plate. All the lower bolts started to shear.

Specimen 7.-Twelve-inch and 14-inch $\mathrm{H}$ sections, single splice plates, loads perpendicular to web, bearing plate between ends of $\mathrm{H}$ sections. Figure 6 shows the specimen after failure. The lower splice plate failed in tension on the net section through the holes nearest the end of the 14-inch $H$ section.

A brief summary of the way in which the specimens failed is given in Table 1. 


\section{B. S. Journal of Research, RP157}

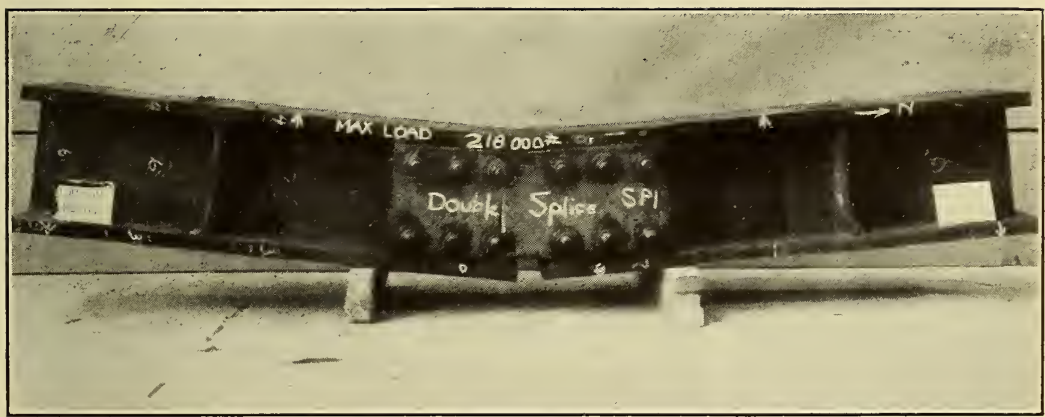

FIgURE 10.-Specimen 2 after transverse test; 10-inch $\mathrm{H}$ sections; double splice plates; loads parallel to web of $\mathrm{H}$ section

Splice plates failed in tension. Specimen 1 failed in a similar way.

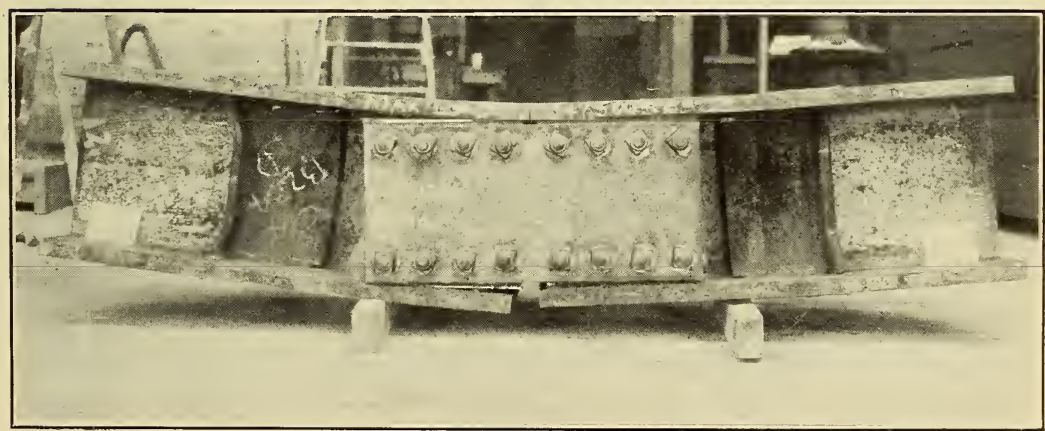

FiguRe 11.-Specimen 4 after transverse test; 14-inch $\mathrm{H}$ sections; double splice plates; loads parallel to web 
B. S. Journa! of Research, RP157

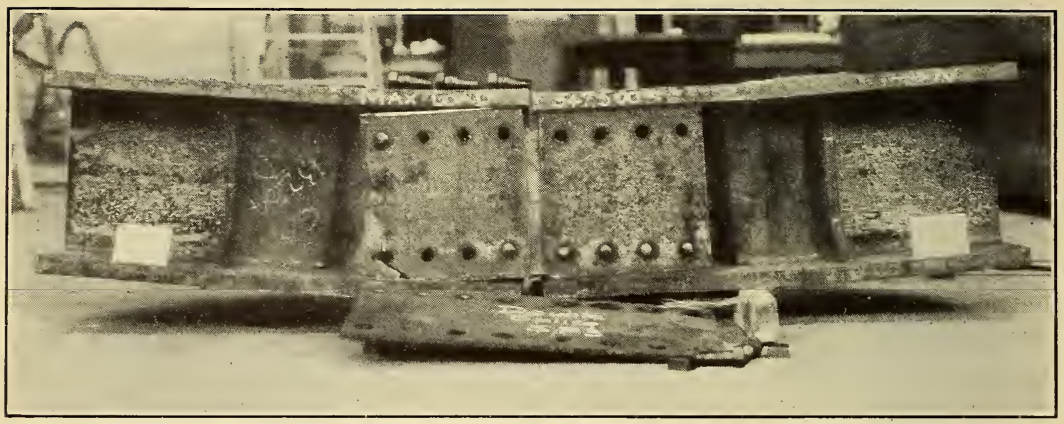

FIGURE 12.-Specimen 4 after transverse test with outside splice plates removed; 14-inch $\mathrm{H}$ sections; double splice plates; loads parallel to web

Welded plates failed along lower line of bolts; welds sheared; bolts started to shear.

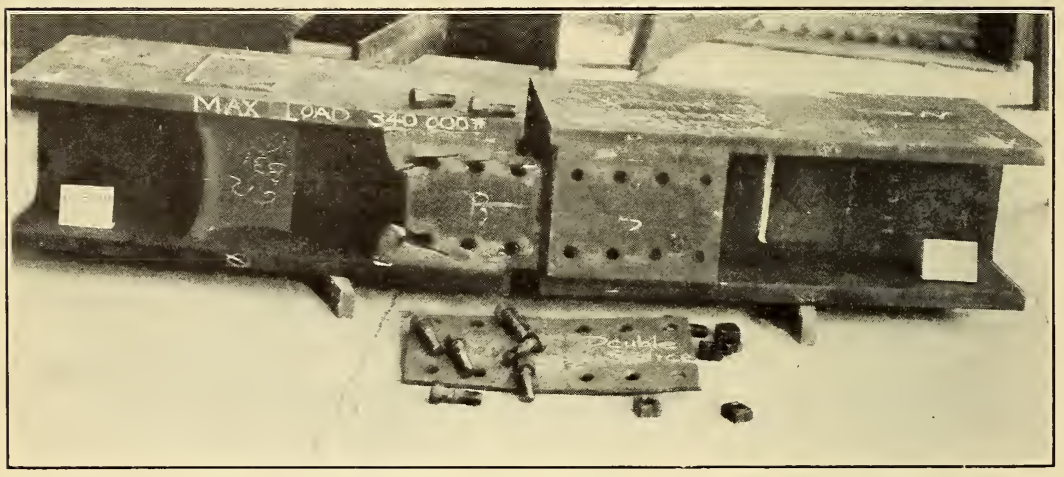

FIGURE 13.-Specimen 6 after transverse test with lower splice plate removed; 12-inch $\mathrm{H}$ seciions; double splice plates; loads perpendicular to web

Welded plates failed in bearing on bolts and sheared lengthwise; welds failed near ends. 


\section{ANALYSIS OF DATA}

\section{STRESS}

The stresses in the specimens were computed using the common or Euler-Bernoulli theory of beams. Although the use of this theory for these specimens is open to a number of objections which will be discussed later, the data at hand did not warrant the use of a more refined theory. The computed stresses in the different parts of the specimens are given in Table 1. The analysis of stress will be explained for specimen 4 to show how the computations are made.

With equal loads applied at the quarter points of the beam as shown in Figures 7 and 14, the bending moment is constant between the loads and equals the product of one-half the total load and one-fourth of the length of the span. The maximum bending stresses occur at the section through one of the group of holes nearest the middle of the span. (Fig. 14.) Here the $\mathrm{H}$ sections are not effective in carrying tensile stress and the area of the splice plates is reduced because of the

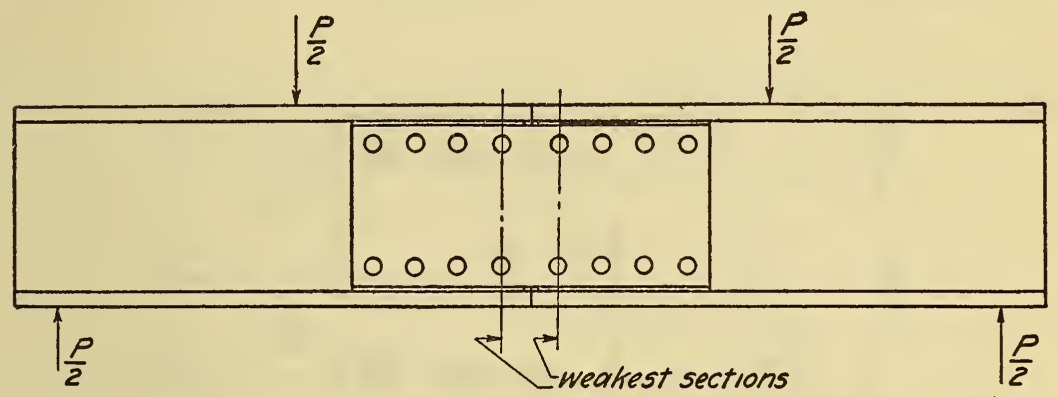

Figure 14.-Diagram showing forces acting on the beam

bolt holes. This section will be referred to as the "weakest section" of the beam.

The maximum bending stress in the splice plates and the $\mathrm{H}$ sections at the weakest section of the beam is given by the formula

$$
S=\frac{M c}{I}
$$

in which

$S$ is the maximum bending stress in tension or compression (lbs./in. ${ }^{2}$ ),

$M$ is the bending moment at the section (lbs.-in.),

$c$ is the distance from the neutral axis to the extreme fiber in tension or compression (in.), and

$I$ is the moment of inertia of the effective cross section (in. ${ }^{4}$ ).

At the weakest section the splice plates act as beams. The upper part is in compression and the lower part is in tension with the neutral axis as the line of zero stress. The $\mathrm{H}$ section does not here act as a beam since there is no way in which it can carry tensile stress. The compressive stress varies from a maximum in the outer fibers to zero along some axis lower in the $\mathrm{H}$ section. The gravity axis of the areas assumed to carry stress was taken as the neutral axis. Included in the area effective for carrying compressive stress is a 
small portion of the web of the $\mathrm{H}$ section lying between the neutral axis and the upper flange. Its effect on the position of the neutral axis and the value of the moment of inertia is small. Its effect on stress values is less than 2 per cent. Because of the shorter and simpler computations which resulted, this area has been neglected.

The portions of the specimens which are assumed to carry stress at the weakest section are shown by full lines in Figures 2 to 5 . The portions above the neutral axis are in compression and those below the neutral axis are in tension. The portion indicated by dash lines do not carry stress at the weakest section. The area of the bolt holes was deducted for all splice plates except the upper plates on specimens 5,6 , and 7 .

After computing the location of the neutral axis (gravity axis), the magnitude of the moments of inertia and the maximum tensile and compressive stresses, the reactions between the splice plates and the bolts must be determined before the stresses in the bolts can be obtained. For the specimens having the splice plates vertical, Figure 15 shows the part of the splice plates on one side of a sec-

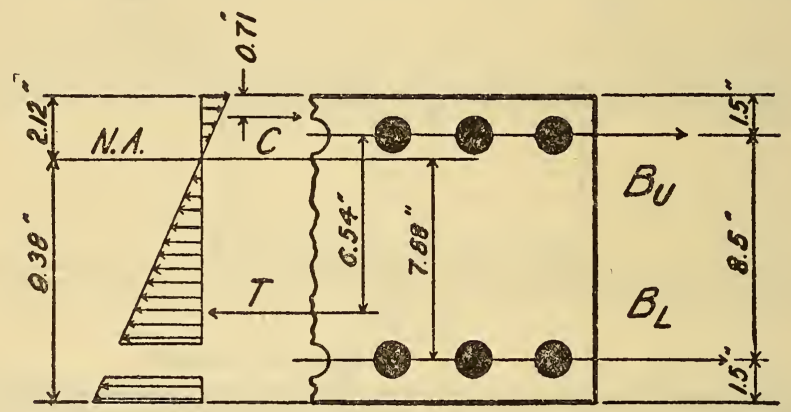

FIgURE 15.-Free-body diagram showing forces acting on a splice plate

tion through the inner group of bolt holes and also the forces acting on it. The forces are the stresses on the cut sections and the reactions of the bolts on the plates. There are no vertical forces, since the shear in the beam is zero between the loads. The frictional forces between the splice plates and welded plates are indeterminate and have been neglected.

Let $C=$ the resultant compressive force on the upper portion of the plates. It acts at the third point of the distance between the top of the plate and the neutral axis.

In computing $C$, for specimen 4 at the maximum load, the compressive stress at the upper edge of the splice plates from formula 1 is $S_{c}=\frac{4,516,900 \times 2.12}{583}=16,420 \mathrm{lbs} . /$ in. $^{2}$.

The average stress is $\frac{16,420}{2}=8,210 \mathrm{lbs}$./in. ${ }^{2}$.

The total area above the neutral axis for the four splice plates is $4 \times \frac{7}{16} \times 2.12=3.70$ square inches.

$$
C=8,210 \times 3.70=30,400 \text { pounds }
$$


Let $T=$ the resultant tensile force on the lower portion of the plates. The stress on the outer fiber has been found to be 72,700 lbs./in. ${ }^{2}$ The stress at the axis of the holes is then $72,700 \times \frac{7.88}{9.38}=$ $61,100 \mathrm{lbs} . /$ in. $^{2}$ As no stress is transmitted across the portion of the section through the bolt holes, $T=\frac{1}{2} \times 72,700 \times 9.38 \times 4 \times \frac{7}{16}-61,100 \times$ $\frac{15}{16} \times 4 \times \frac{7}{16}=496,800$ pounds.

The arm of $T$ about the neutral axis, as found by taking moments about the neutral axis, is:

$$
\begin{aligned}
& {\left[\left(\frac{72,700}{2} \times 9.38 \times \frac{7}{16} \times 4\right) \times \frac{2}{3} \times 9.38\right]} \\
& -\left[\left(61,100 \times \frac{15}{16} \times \frac{7}{16} \times 4 \times 7.88\right) \times 7.88\right] \\
& \frac{496,800}{=5.92 \text { inches } .}
\end{aligned}
$$

The reactions of the bolts, $B_{L}$ and $B_{U}$, may now be found from the principles of statics for parallel forces. To find $B_{L}$ take moments about the line of action of $B_{U}$.

The arm of $T$ about $B_{U}=5.92+0.62=6.54$ inches.

The arm of $C=1.50-0.71=0.79$ inch.

$$
\begin{array}{ll}
\Sigma M=0 & B_{L} \times 8.5-496,800 \times 6.54-30,400 \times 0.79=0 . \\
& B_{L}=385,000 \text { pounds. } \\
\Sigma F=0 & B_{U}+30,400+385,000-496,800=0 . \\
& B_{U}=81,400 \text { pounds. }
\end{array}
$$

$B_{U}$, therefore, acts in the same direction as $B_{L}$ and $C$.

There are eight bolts in double shear on each side of the joint so the area in shear is $16 \times 0.60=9.60$ in. $^{2}$ The average shearing stress in the lower bolts is:

$$
S_{s}=385,000 \div 9.60=40,100 \text { lbs. } / \text { in. }{ }^{2} .
$$

The area in bearing is $8 \times \frac{7}{8} \times \frac{7}{16}=3.06$ in. ${ }^{2} \quad$ The average bearing stress in the lower bolts and the welded plates in contact with these bolts is:

$$
S_{c}=385,000 \div 3.06=125,800 \mathrm{lbs} . / \text { in }^{2}
$$

To determine the forces, $W_{L}$ and $W_{U}$, acting on the welds, consider the welded plates shown in Figure 16 in equilibrium under the known reactions of the bolts and the unknown forces acting at the welds. The forces are parallel and the values of the unknown forces may be found from the conditions that $\Sigma F=0$ and $\Sigma M=0$.

$$
\begin{array}{ll}
\Sigma M=0 & W_{L} \times 12.40-385,000 \times 10.45-81,400 \times 1.95=0 . \\
\Sigma F=0 & W_{L}=337,300 \text { pounds. } \\
& W_{U}+337,300-385,000-81,400=0 . \\
& W_{U}=129,100 \text { pounds. }
\end{array}
$$


The length of weld on both plates is $2 \times 12=24$ inches. The average shearing stress in the lower welds is:

$$
S_{s w}=337,300 \div 24=14,100 \mathrm{lbs} . / \mathrm{lin} \text {. in. }
$$

The computations for finding the stresses in the bolts and welds of specimens with loads parallel to the web are somewhat laborious.

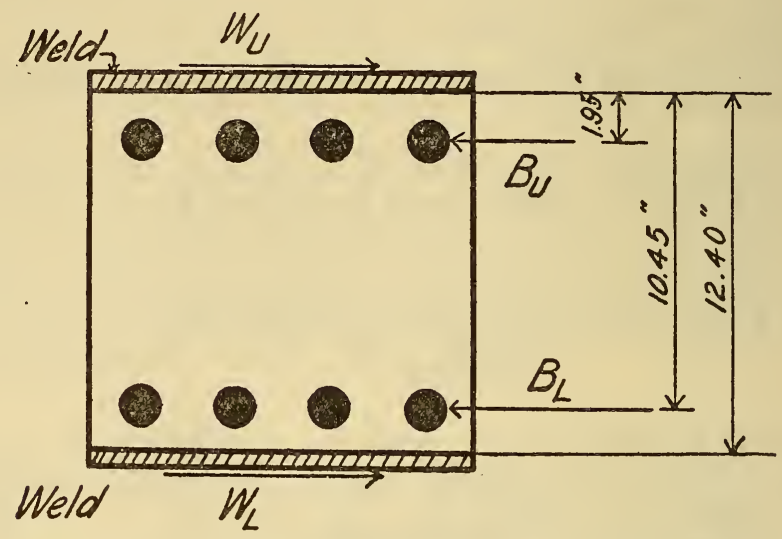

FigURe 16.-Free-body diagram showing forces acting on a welded plate

An alternate method which involves one additional approximation may be used. It is shorter, and the results are probably as accurate as the data warrant.

The free-body diagram of a part of one $\mathrm{H}$ section together with the plates welded to it is shown in Figure 17. The $\mathrm{H}$ section is assumed to be cut at a point between the ends of the welded plates and the

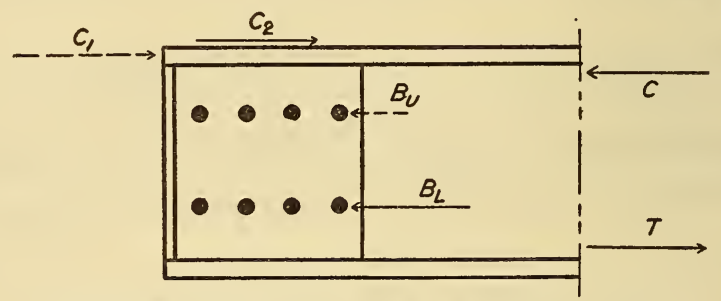

FIgURe 17.-Free-body diagram showing forces acting on a welded plate and $a$ portion of an $\mathrm{H}$ section

$C_{2}$ is the resultant of $C_{1}$ and $B U$.

applied load so that the bending moment at the cut section is equal to the constant moment in the middle half of the beam. The forces acting across the cut section are the bending stresses in the beam. These vary from zero at the neutral axis to a maximum at the extreme fiber. The compressive and the tensile forces may be replaced by their resultants $C$ and $T$. These constitute a couple whose moment is equal to the bending moment in the beam. The other forces acting on the free body are the bolt reactions, $B_{U}$ and $B_{L}$, and the reaction between the ends of the two $\mathrm{H}$ sections, $C_{1}$. If $C_{1}$ and $B_{U}$ 
are replaced by their resultant $C_{2}$, a second couple consisting of $C_{2}$ and $B_{L}$ is obtained. This couple balances the couple consisting of $C$ and $T$ and, therefore, its value is also equal to the bending moment in the beam. By computing values for different positions of $C_{2}$ it has been found that $C_{2}$ may be assumed to act along the outside face of the upper flange for specimens similar to the ones included in these tests.

The values of $B_{L}$ may now be found by dividing the bending moment by the distance of $B_{L}$ from the upper face of the specimen. For specimen 4 , at the maximum load,

$$
\begin{aligned}
& B_{L}=4,516,900 \div 11.70=386,000 \text { pounds. } \\
& S_{s}=386,000 \div 9.60=40,200 \text { lb./in. }{ }^{2} . \\
& S_{c}=386,000 \div 3.06=126,200 \text { lbs./in. }{ }^{2} \text {. }
\end{aligned}
$$

The forces acting on a part of one $\mathrm{H}$ section without welded plates are shown in Figure 18. Replace $C_{1}$ and $W_{U}$ by their resultant $C_{3}$

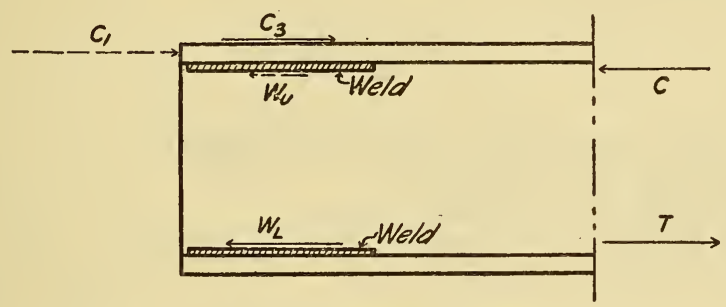

Figure 18.-Free-body diagram showing forces acting on a portion of an $\mathrm{H}$ section

$C_{3}$ is the resultant of $C_{1}$ and $W_{U}$.

acting along the outer face of the upper flange. The arm of the couple consisting of $C_{3}$ and $W_{L}$ is 13.65 inches.

$$
\begin{aligned}
& W_{L}=4,516,900 \div 13.65=331,000 \text { lbs. } \\
& S_{s w}=331,000 \div 24=13,800 \text { lbs./lin. in. }
\end{aligned}
$$

The values of the stresses in the bolts and in the welds of specimens 1 to 4 computed by both methods explained above are given in Table 2 .

\begin{tabular}{|c|c|c|c|c|}
\hline Specimen & Method & $\begin{array}{l}\text { Maximum } \\
\text { shearing } \\
\text { stress in } \\
\text { lower row } \\
\text { of bolts }\end{array}$ & $\begin{array}{l}\text { Maximum } \\
\text { bearing } \\
\text { stress of } \\
\text { lower bolts } \\
\text { and plates }\end{array}$ & $\begin{array}{l}\text { Maximum } \\
\text { shearing } \\
\text { stress in } \\
\text { lower welds }\end{array}$ \\
\hline No. 1 & First & $\begin{array}{c}\text { Lbs./in. }{ }^{2} \\
30,400\end{array}$ & $\begin{array}{l}\text { Lbs./in. }{ }^{2} \\
55,500\end{array}$ & Lbs./in. ${ }^{2}$ \\
\hline No. 2 & $\begin{array}{l}\text { Second } \\
\text { First__ }\end{array}$ & $\begin{array}{l}31,300 \\
33,000\end{array}$ & $\begin{array}{r}57,300 \\
120,500\end{array}$ & $\begin{array}{r}5,230 \\
11,500\end{array}$ \\
\hline No. 3 & $\begin{array}{l}\text { Second. } \\
\text { First.- }\end{array}$ & $\begin{array}{l}33,200 \\
39,800\end{array}$ & $\begin{array}{r}122,000 \\
62,300\end{array}$ & $\begin{array}{r}11,150 \\
7,170\end{array}$ \\
\hline No. 4 & $\begin{array}{l}\text { Second.-.:- } \\
\text { First_. }\end{array}$ & $\begin{array}{l}41,000 \\
40,100 \\
40,200\end{array}$ & $\begin{array}{r}64,200 \\
125,800 \\
126,200\end{array}$ & $\begin{array}{r}7,050 \\
14,100 \\
13,800\end{array}$ \\
\hline
\end{tabular}
The values by the second method agree closely with those computed by the first method. In all but three cases the difference is on the side of safety and in these cases the difference is less than 4 per cent.

TABLE 2.-Comparison of stresses computed by different methods 
In general, the method of computing the value of the stresses in the specimens with loads perpendicular to the web are the same as those for the specimens with loads parallel to the web. (See specimen 5, fig. 4.)

Dividing the total tension in the lower plate by the areas of the bolts in shear and in bearing and by the length of the welds in shear gives the average stresses to which they are subjected.

\section{DEFLECTION}

Each of the dash lines in Figures 8 and 9 represents the deflection of a beam of constant cross section loaded at the quarter points and having a moment of inertia numerically equal to that of the computed value of the moment of inertia at the weakest section of the corresponding test beam.

This deflection is given by the formula

$$
y=\frac{11 P l^{3}}{768 E I}
$$

in which $y$ is the deflection at midspan (inches)

$P$ is the total load (pounds)

$l$ is the span of the beam (inches)

$E$ is the modulus of elasticity (lbs./in. ${ }^{2}$ ) and

$I$ is the moment of inertia (in. ${ }^{4}$ )

\section{DISCUSSION}

\section{METHOD OF ANALYSIS}

The formula, $S=\frac{M c}{I}$, should preferably be used to compute bending stresses in a beam only when the beam is long compared with its cross-sectional dimensions, the beam is constant in cross section throughout its length, and the bending stresses are below the proportional limit of the material. In these specimens the span of the beam was about five times the greatest cross-sectional dimension, which is below the values for which the common beam theory is applicable. There was a marked change in cross section at the splice, and the beams were loaded to failure.

The use of the beam formula for ultimate loads was analogous to its use in finding the modulus of rupture. Stresses computed from the ultimate load may be expected to hold closely for other specimens of the same size, shape, and loading, and approximately for those of similar size, shape, and loading. They should not be used as a basis for the design of widely different types of connections without further test.

For abrupt changes of cross section, such as occur in the neighborhood of the weakest section, there is no assurance that proportionality of stress to strain exists as was assumed in computing the bending stresses from their distance from the neutral axis determined according to the assumptions made in the analysis.

As the limit of proportionality of deflection to load was fairly definite for these specimens, the stresses corresponding to the "yield- 
point" loads can probably be used for design purposes because these stresses in the various parts of the spliced connection correspond to the maximum deflection to which the splice should be subjected. The stresses corresponding to the maximum loads are also given since these loads caused known changes in the specimens and the computed stresses serve as a criterion for determining the value of the analysis.

In developing a method of analysis which can be used in the design of details with complex stress distribution, assumptions such as these may give results that differ widely from the actual stress conditions in the specimen. Nevertheless, the analysis can be used in design if it gives values of stress which are consistent; that is, if for any type of failure the values of stress computed for specimens that failed are higher than those which were computed for specimens which did not fail. An ultimate value of stress for design of similar connections may then be set which is below the values at which failure occurred in the tests. In this investigation the stresses at which failure occurred were, with one exception, greater than the corresponding stresses at which there was no failure. For the exception, the difference in the value of stress is less than 5 per cent. Moreover, the computed values at which failure took place are equal to or slightly above the ultimate strength of structural steel in tension, shear, and bearing so that these ultimate values may be used in designing similar connections.

\section{STRESS}

(a) H SECTIONS

The values of the compressive stresses in the $H$ sections were low due to the short distance between the neutral axis and the extreme fibers.

(b) PLATES

Specimens 1, 2, and 7 failed by rupture of the splice plates in tension at computed stresses of from 68,600 to 83,200 lbs./in. ${ }^{2}$. These computed stresses exceed the probable ultimate strength of the material in tension. A design based on an ultimate tensile strength of structural steel of $65,000 \mathrm{lbs}$./in. ${ }^{2}$ with a proper factor of safety should result in a splice of adequate strength in tension.

In two other instances the plates did not have sufficient strength to resist the stress to which they were subjected. The plates in specimen 5 bowed up as has been explained. In specimen 6 one welded plate sheared lengthwise. Based on the net area of a section through the bolt holes the shearing stress in this plate was 45,800 lbs./in. ${ }^{2}$ It is evident that in the design of a connection the strength of the plates should be computed to insure that they will not fail as in specimens 5 and 6 .

\section{(c) BOLTS}

The bolts in specimen 3 sheared at a computed stress of 39,800 lbs./in. ${ }^{2}$. In specimen 4 , in which the splice plates failed in bearing, the bolts had commenced to shear at a computed stress of 40,100 lbs./in. ${ }^{2}$. These values are probably somewhat in excess of the ultimate strength of rough bolts in shear. For purposes of design this may be taken at 32,000 to $35,000 \mathrm{lbs} . / \mathrm{in} .^{2}$. 
Four bolts in specimen 5 sheared at a computed stress of 35,000 lbs./in. ${ }^{2}$. The splice plate and welded plates on the lower side of this specimen bowed up. This produced shearing stress in the bolts at right angles to the shear considered in the analysis. The value of the resultant shear may well have been in the neighborhood of those shown by the other specimens that failed in shear. The fact that not all the bolts sheared favors this explanation since the bending of the plates with consequent transverse shear increased toward the middle of the splice plate.

Signs of failure in bearing in the splice plates occurred at average bearing stresses of 109,000 to $125,800 \mathrm{lbs}$./in. ${ }^{2}$. Designs of similar joints on the basis of allowable stresses of 90,000 to $100,000 \mathrm{lbs}$./in. ${ }^{2}$. in bearing for structural steel should give splices of adequate strength.

In addition to shear and bearing, the bolts are also subjected to bending. In computing the bending stress in pins in pin-connected structures it is customary to assume that the loads on the pins are concentrated loads acting along the center line of the surface of contact. Since the thickness of the plates is only a small part of the arm of the forces, this method gives results which are sufficiently accurate. If the same method were used to compute the bending stress in the bolts in these specimens, relatively large errors would be introduced, since the moment arm of the forces would equal the thickness of one plate.

An exact analysis of the problem is not possible nor is it necessary. The bolt may be considered as a continuous beam on elastic supports under distributed load. The bending stress under such conditions will evidently be much less than if the same load is considered as concentrated and acting on a simple beam. Moreover, the effect of the nut on the bolt will be to reduce the bending, due to the loads applied to the bolt by the plates. Because of the uncertainty of any assumptions concerning the distribution of the loads on the bolts and on account of the absence of any definite indications of failure due to bending, no attempt has been made to analyze the bending stress in the bolts.

\section{(d) WELDS}

Several welded seams of specimen 4 failed at a computed stress of $14,100 \mathrm{lbs}$./lin. in. after the maximum load on the specimen had been reached. The welds of specimens 5 and 6 failed for a short distance at the ends at average computed stresses of 7,000 to 11,800 lbs./lin. in., respectively. These weld failures were due to local concentration of stress at the ends of the welds after the specimens had begun to fail elsewhere. The computed weld stresses are, therefore, not indicative of the full strength of the welds. In no case did failure of the specimens begin in the welds. Welds designed according to the provisions of the code for fusion welding in building construction formulated by the American Welding Society should be adequate in strength.

\section{DEFLECTION}

Figures 8 and 9 show that the load-deflection curves begin to deviate from a straight line at low values of load. This would indicate that portions of the connections were subjected to relatively high stresses at low loads with consequent redistribution of stress in the connections.

For specimens with loads parallel to the web there is a fairly close agreement between the observed values of deflection and 
the computed deflection of a beam similarly loaded and having a moment of inertia throughout its full length equal to that computed for the weakest section of the splice of the actual beam. The ratio of this moment of inertia to that of the $\mathrm{H}$ section varied from 0.13 to 0.30 . There is no assurance, however, that this agreement would hold for other lengths of span and methods of loading or for other ratios of moments of inertia. For specimens with loads perpendicular to the web, the actual deflection of the specimens was from 50 to 100 per cent greater than that of beams with a constant moment of inertia equal to that of the splice. The ratio of the moment of inertia at the weakest section of the splice to that of the $\mathrm{H}$ section varied from 0.56 for the 14 -inch $\mathrm{H}$ section of specimen 7 to 1.03 for specimen 6 .

\section{COMBINED LOADING}

In an actual structure the column connections are not only subjected to bending stresses, but are also called upon to assist in transferring direct loads from one column to another. The relative magnitude of the stresses due to direct load and bending will depend among other things on the size and shape of the building and the position of the column in it. In these connections, considered as simple beams, the maximum compressive stresses are small. Considering the column under the action of both types of loading, the compressive stress becomes of major importance and the column may be expected to fail in compression before the ultimate strength of the connection in bending is reached.

The splice will also be subjected to forces which cause bending and shearing of the splice. Transverse shearing of the splice is resisted by the frictional force developed between the ends of the columns and by the shearing stress developed in the splice plates. When the direction of the forces causing shear is perpendicular to the plane of the splice plates, local bending in the plates and tension in the bolts may also be produced. The stresses thus developed should be considered in connection with those caused by bending of the splice.

\section{CONCLUSIONS}

The conclusions formed from tests of steel columns consisting of $\mathrm{H}$ sections 3 feet long and 10,12, and 14 inches wide, connected with splice plates bolted to plates welded between the flanges of the $\mathrm{H}$ sections, and tested as simple beams with equal loads at the quarter points of a 66-inch span are:

1. The analysis of stress in these specimens using the simple beam theory gives maximum stress values in the connections which are consistent with the ultimate strength of structural steel.

2. Similar column splices having adequate factors of safety may be designed by these methods on the basis of the values of stresses prescribed by standard building codes for structural steel.

Washington, September 13, 1929. 